\title{
AISI H13 VE AISI D2 ÇELÍKLERİNİN DELİNMESİ ESNASINDA KESME BÖLGESİNDE OLUŞAN SICAKLIĞA KESİCI TAKIM KAPLAMASININ VE İŞLEME PARAMETRELERİNİN ETKİSİ
}

\author{
İsmail TEKAÜT ${ }^{1}$, Halil DEMİR ${ }^{2}$ \\ ${ }^{1}$ Gazi Üniversitesi, Teknik Bilimler MYO, Ankara / Türkiye \\ ${ }^{2}$ Karabük Üniversitesi, Teknoloji Fakültesi, İmalat Mühendisliği Karabük / Türkiye \\ ismailt@gazi.edu.tr, hdemir@karabuk.edu.tr
}

(Geliş/Received: 13.06.2014; Kabul/Accepted: 01.12.2014)

ÖZET

\begin{abstract}
Delik delme işleminde, takım ve işlem performansı için sıcaklık önemli bir faktördür. Bu nedenle kesme bölgesinde oluşan sıcaklığın analiz edilmesi işlem performansının tahmin edilebilmesi açısından önemlidir. $\mathrm{Bu}$ amaçla, sanayide sıkça kullanılan AISI H13 ve AISI D2 malzemeleri $14 \mathrm{~mm}$ çapında kaplamasız ve (AlCrN monolayer) kaplamalı karbür matkaplarla dik işleme merkezinde delinmiştir. Kesme bölgesinde oluşan sıcaklıklar matkapların soğutma kanallarına yerleştirilen ısıl çiftler yardımıyla ölçülmüş̧ür. Deneylerde dört farklı kesme hızı $(60,75,90$ ve $108 \mathrm{~m} /$ dak $)$ ve üç farklı ilerleme miktarı $(0.15,0.20$ ve $0.25 \mathrm{~mm} / \mathrm{dev})$ kullanılmıştır. Deneysel çalışma sonucu, ilerleme miktarı ve kesme hızı artışı sıcaklığın azalmasına yol açmıştır. Kaplamalı matkapların kaplama özelliğinden dolayı ısı iletim katsayısının düşük olması, kaplamalı matkaplarla yapılan işlemlerde sıcaklığın daha fazla olmasına neden olmuştur. Bütün deneylerde, AISI H13 malzemesinin işlenmesi esnasında oluşan sıcaklık değerleri AISI D2 malzemesinin işlenmesi esnasında oluşan sıcaklık değerlerinden daha fazla çıkmıştır. Bu duruma malzemelerin yapısal ve kimyasal farklılıklarının neden olduğu düşünülmektedir.
\end{abstract}

Anahtar Kelimeler: Delik delme, AISI H13 çeliği, AISI D2 çeliği, takım kaplaması, sıcaklık ölçümü

\section{THE EFFECTS OF CUTTING TOOL COATING AND MACHINING PARAMETERS IN DRILLING OF STEEL AISI H13 AND AISI D2}

\begin{abstract}
In drilling, temperature is an important factor for the tool and the machining performance. For this reason, analysis of the temperature in the cutting zone is essential for predicting the machining performance. In this study, commonly used AISI H13 and AISI D2 steels were drilled using uncoated and (AICrN monolayer) coated carbide drills of $14 \mathrm{~mm}$ diameter on a vertical machining centre. The cutting zone temperatures were determined using the thermocouples inserted into the coolant holes of the drills. The tests were carried out at four different cutting speeds $(60,75,90$ and $108 \mathrm{~m} / \mathrm{min})$ and three different feed rates $(0.15,0.20$ and $0.25 \mathrm{~mm} / \mathrm{rev})$. The experimental results showed that increasing feed rate and cutting speed led to decrease in the temperature. The lower heat conduction of the coated drills resulted in the higher temperature. In all the tests, drilling of AISI H13 caused higher temperature than that of AISI D2. It is considered that this was caused by the structural and chemical differences of the materials.
\end{abstract}

Keywords: Drilling, AISI H13, AISI D2, tool coating, temperature measurement

\section{GİRIŞ (INTRODUCTION)}

Talaş kaldırma işlemi esnasında kesici takım ve iş parçası ara yüzeyinde, sürtünmeden dolayı yüksek sıcaklıklar oluşmaktadır. Bu sıcaklıklar; kesici takım ömrünü ve çalışma performansını etkilemektedir. Bu nedenle talaş kaldırma işlemlerinde kesici takım ve iş parçası ara yüzeyindeki sıcaklık, işlemin verimliliği 
için önemlidir. Dolayısıyla talaş kaldırma işlemlerinde kesme bölgesinde oluşan sıcaklığın araştırılması ve bu araştırmalar neticesinde iş parçasıtalaş-takım arasında oluşacak sıcaklığın tahmin edilmesi hem iş parçası-kesici takım malzemesi çifti seçiminde yol göstererek daha verimli talaş kaldırmasına katkı sağlayacaktır. Delik delme işlemi diğer talaş kaldırma işlemlerinde olduğu gibi aynı talaş kaldırma kinematiğine sahiptir. Fakat tornalama ve frezeleme işlemlerin aksine delik delme işleminin kapalı alanda gerçekleşmesi işlemin gözlenebilirliğini sınırlandırmaktadır. Ayrıca delik delme işlemlerinde talaşın işlenen delik cidarları ve matkap gövdesine uzun süre temas ederek tahliye edilmesi sebebiyle, diğer kesme işlemlerinden farklı olarak, talaşla atılan ısının tekrar iş parçası ve matkaba geri transfer olmasina sebep olmaktadır. $\mathrm{Bu}$ durum kesme bölgesinde oluşan sıcaklığın, diğer işleme yöntemlerinden daha yüksek çıkmasına sebep olurken talaşla tahliye edilen 1Sı miktarının azalması, iş parçası ve takıma transfer olan ısının artmasıyla sonuçlanmaktadır [1]. Bu nedenle delik kalitesinin daha iyi olması için işlem esnasında oluşan sıcaklığın belirlenmesi ve olumsuz etkilerinin bertaraf edilmesi için araştırmalar kaçınılmaz olmuştur. Şahin ve Acır, talaş kaldırma esnasında ortaya çıkan 1 sının \% 1020’lik kısmının takıma aktığını ve bu 1sının kesici takımda mekanik gerilmelerin yanı sıra şiddetli 1 sıl gerilmelere yol açarak kesici takım yorgunluğu, 1sıl kırılma, aşınma ve bunun gibi istenmeyen durumlara sebep verdiğini belirtmişlerdir [2]. Ueda ve arkadaşları delik delme, tornalama ve frezeleme işlemlerinde kuru şartlarda ve kesme sıvısı kullanarak sıcaklık ölçümü yapmışlardır. Yaptıkları çalışmada talaş kaldırma işlemlerinde en yüksek sıcaklığın delik delme işlemlerinde, ikinci sırada tornalama işlemlerinde ve en düşük sıcaklığın ise frezeleme işlemlerinde oluştuğunu belirlemişlerdir [3]. Ghani ve arkadaşları, AISI H13 çeliğinin frezelenmesinde, kesme hızının artmasıyla birlikte sıcaklığın artarak yüksek mekanik zorlanmaya sebebiyet verdiğini ve takım kenarlarında erken çatlak ve aşınmalar oluştuğunu belirtmişlerdir [4]. Umbrello ve arkadaşları, farklı sertliklerde ki AISI H13 çeliğinin işlenmesinde oluşan talaş şeklinin iş parçasının sertliğine göre değiştiğini ve sertlik artışıyla talaş kırılmalarının artarak kırılma boyunun kısaldığını ifade etmişlerdir [5]. Moon ve arkadaşları, kimyasal kompozisyonları farklı, tavlanmış ve suda sertleştirilmiş takım çeliklerinin tornalanmasında ve delinmesinde TiC kaplamalı sementit karbür takımlar kullanmışlardır. Tavlamış çeliklerin işlenmesinde en yüksek kesme kuvvetinin AISI H13 çeliğinde oluştuğunu ve AISI L6 (ESC) çeliğinde diğer tüm çelik türlerinden daha kolay işlenebilirliğe sahip olduğunu vurgulamışlardır [6]. Davim ve arkadaşı, seramik takımlarla AISI D2 çeliğinin sert tornalanmasında, kesme hızının yükselmesiyle birlikte aşırı derecede yanak aşınmasının oluştuğunu tespit [7]. Poulachon ve arkadaşları, aynı sertlikte ki AISI
D2, AISI H11, 35NiCrMo16 ve AISI 52100 çeliklerini CBN kesici takımlarla işlemişler ve takım aşınmasına en etkili faktörün iş parçalarının mikro yapılarında bulunan karbür oluşumların olduğunu tespit etmişlerdir. Kesme hızının artışıyla takım aşınmasının arttığını ve iş parçasının mikro yapısında bulunan karbürlerin kesme sıcaklığından etkilenmediğini belirtmişlerdir [8]. Silva ve arkadaşı, AISI 1040 çeliğinin tornalanması esnasında, kesme hızının, ilerleme miktarının, kesme derinliğinin ve talaş-kesici takım temas süresinin artışıyla sıcaklık değerlerinin artış gösterdiğini gözlemlemişlerdir [9]. Haan ve arkadaşları, CNC dik işlemede SAE 308 ve 390 malzemelerini $25 \mathrm{~mm}$ delik boyunda $4.5 \mathrm{~mm}$ çapında matkaplarla delmişlerdir. İlerleme miktarının artmasıyla talaşın kalınlaştığını, soğutma sıvısı kullanıldığında talaşın daha kıvrımlı olduğunu, ilerleme kuvvetinin ilerleme miktarının artışıyla artı̆ğını tespit ederek, ilerleme kuvveti ve momentin matkap malzemesi ve uç açısıyla değiştiğini belirtmişlerdir. Kesme hızı, ilerleme miktarı ve iş parçası malzemesinin sıcaklığın artışında önemli etken olduğunu gözlemlemişlerdir [10]. Bağcı ve arkadaşı, delik delme işlemini sabit matkap-dönen iş parçası tertibi ile gerçekleştirerek, sıcaklığı matkapların soğutma kanallarına yerleştirdikleri 1sıl çiftler vasıtasıyla ölçmüşlerdir. Aynı matkapla delik delme sayısı ve ilerleme miktarı arttıkça kesme kuvvetlerinin de arttığını belirlemişlerdir [11]. Brandao ve arkadaşları, AISI H13 çeliğinde, aşınmış matkaplara göre yeni matkaplarla yapılan delik delme işleminde, ölçülen sıcaklığın, ilerleme kuvvetinin, moment değerlerinin düşük çıktığını ve soğutma sıvısı kullanım miktarı ile sicaklığın azalmasının orantılı olduğu tespit etmişlerdir [12]. Coz ve arkadaşları, havacılık alaşımlarını frezeleme ve delik delme işlemlerinde kesici takımlarda oluşan sıcaklığın matkap uç geometrisinin önemli faktör olduğunu ve kaplamalı matkaplarda sıcaklık değerlerinin daha düşük olduğunu belirlemişlerdir [13]. Yağmur ve arkadaşları, AISI 1050 malzemesini 14 mm çapında kaplamasız ve kaplamalı karbür matkaplarla işleyerek sicaklık, kesme kuvvetleri, moment ve delik kalitesini araştırmışlardır. Matkapların soğutma kanallarına konumlandırılmış 1sıl çiftler aracılıyla sıcaklığı ölçerek, sıcaklığın ilerleme miktarının artmasıyla birlikte azaldığını belirlemişlerdir. İlerleme miktarı artışına karşın sıcaklığın azalmasını daha hızlı talaş tahliyesi ve matkap - talaş temas süresinin daha kısa olmasına yorumlamışlardır [14]. Kaynak, kaplamalı ve kaplamasız farklı uç açılı helisel matkaplarla, Al 2024-T4 iş parçasına kuru kesme şartlarında delmiş ve en yüksek sıcaklık değerini $118^{\circ}$ uç açılı kaplamasız matkapla, en az sicaklık değerini ise $130^{\circ}$ uç açılı kaplamalı matkapla yapılan işlemlerde elde etmiştir [15]. Sousa ve arkadaşları, $10 \mathrm{~mm}$ çapında kaplamalı takımlar ile yüksek dirençli, düşük alaşımlı (HSLA) çeliğin delinmesi sırasında oluşan sıcaklıkları K tipi ısıl çiftler kullanılarak ölçmüşlerdir. Sıcaklığın, matkabın iş parçası içerisinde ilerlerken ilk 10 sn' de 
matkap ucu ve çevresine, 170 sn sonra ise iş parçasının tümüne iş parçasının ısı iletkenliği bağlı olarak yayıldığını tespit etmişlerdir [16]. Li, yüksek hızda Ti-6A1-4V titanyum alaşımının, sabit matkapdönen iş parçası tertibatında delinmesi esnasında sıcaklık ve gerilim dağılımını incelemiştir. Sıcaklık ölçümleri için 1 sıl çiftleri matkap kesici kenarına yakın yerlere konumlandırarak, delme işlemi esnasında matkabın delmeye başladığı yerden 10.2 mm'ye kadar ki derinliğe kadar sicaklığın artarak yükseldiğini, bu derinliğie ulaştıktan sonra ise sıcaklığın paralel seyir izlediğini gözlemlemiştir [17]. Kayır ve Usta, GGG40 malzemede, kuru şartlarda delik delmede oluşan sicaklığı ölçmüşlerdir. Talaş sıkışmalarının, talaş sürtünmesinin sıcaklığı artırdığını ve bunun talaşın deformasyonunda etkili olduğunu vurgulamışlardır [18]. Aydın ve arkadaşları, talaş kaldırma esnasında kesme kuvveti, talaş kaldırılan bölgenin ve talaşın ayrılma anındaki sıcaklığını ölçerek, talaşın ayrılma anındaki formunu görüntülemişler ve kesici takımda oluşan aşınma miktarını incelemişlerdir. Sonuçta, talaş kaldırma esnasında oluşan sıcaklığın talaş (\% 70), iş parçası $(\%$ 13) ve kesici takım (\% 17) arasında paylaşıldığını ve kesme hızının artmasıyla birlikte kesme bölgesi sıcaklığının da artığını ifade etmişlerdir. Artan sıcaklığın kesici takımda aşınmaya neden olduğunu ve uzun/kısa talaş formlarının işlenebilirlik açısından uygun olduğunu, şerit, dolaşık, karmaşık talaş formlarının ise uygun olmadığını belirtmişlerdir [19].

Literatürde ayrıca bu çeliklerin metalürjik ve mikro yap1 özelliklerinin incelendiği çalışmalara da rastlanmaktadır. Bu çalışmalarda; nitrürleme, borlama ve kroyejenik işlemler gibi uygulamaların çeliğin mikro yapıları üzerindeki etkileri değerlendirilirken niyobyum ilavesi ile özelliklerin iyileştirilmesi konusu da araştırılmıştır [20-24].

Literatürdeki çalışmalarda talaş kaldırma esnasında oluşan sıcaklığın kesici takım aşınmasında en önemli etken olduğu vurgulanmıştır. Dolayısıyla farklı mikro yapilara sahip olan AISI H13 ve AISI D2 malzemelerinin delinmesi esnasında kesme bölgesinde oluşan sıcaklık değerlerinin bilinmesi hem işlenebilirlik açısından hem de iş parçası-kesici takım çiftinin uyumlu seçimi açısından önemlidir. Bu nedenle yapılan çalışmadan elde edilen veriler daha önce yapılan çalışmaları destekler nitelikte olup sanayi uygulamalarında pratik bilgi olarak kullanılabilecek özelliktedir. Çalışmada, AISI H13 ve AISI D2 malzemelerin kaplamalı ve kaplamasız matkaplarla delinmesinde, kesme bölgesinde oluşan sıcaklıklar ölçülmüş ve her iki malzemenin işlenmesi esnasında oluşan sıcaklıklar işleme parametrelerine göre değerlendirilip, veriler karşılaştırmalı olarak yorumlanmıştır.

\section{MALZEME VE METOT (MATERIAL AND METHOD)}

Deneylerde kullanılan AISI H13 ile AISI D2 çelik malzemelerin mikro yapı fotoğrafları Şekil 1'de ve bu malzemelerin kimyasal kompozisyonları Tablo 1'de verilmiştir.

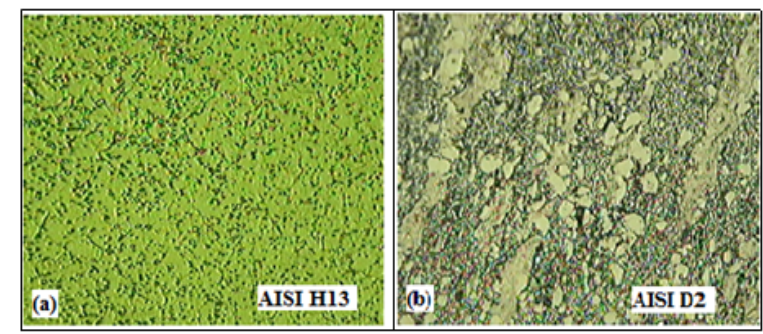

Şekil 1. Malzemelere ait mikro yapı fotoğrafları (Microstructures of the materials).

Malzemelerin sertlik ölçümleri her bir malzeme cinsi için, 10'ar adet deney numunesinin sertlik ölçümleri yapılarak aritmetik ortalaması alınmıştır. Yapılan sertlik ölçümü neticesinde, AISI H13 malzemesinin sertlik değeri $90 \mathrm{HRB}$ (184 HB), AISI D2 çeliğinin ise $96 \mathrm{HRB}(225 \mathrm{HB})$ tespit edilmiştir. Bu çalışmada, matkabın soğutma kanallarından isıl çift geçirme yöntemiyle sıcaklık ölçümü hedeflendiğinden uygulama tipi olarak, sabit kesici takım/dönen iş parçası uygulaması seçilmiştir. Deneylerde, AISI H13 çeliği ve AISI D2 çeliği malzemelerin delinmesinde kaplamasız ve kaplamalı (AICrN monolayer) çok katmanlı yekpare (solid) helisel karbür matkaplar kullanılmıştır. Matkabın ucundaki sıcaklığın ısıl çift ile ölçülebilmesi için ısıl çiftin soğutma kanallarından geçebilecek minimum şartları sağlayan DIN $6537 \mathrm{~K}$ standardında $14 \mathrm{~mm}$ çapında matkap uçları kullanılmıştır. Soğutma kanallarının 1sıl çift

Tablo 1. Malzemelerin kimyasal kompozisyonu (ağırlı \%) (Chemical composition of the materials, weight \%).

\begin{tabular}{|c|c|c|c|c|c|c|c|c|}
\hline \multirow{2}{*}{$\%$ AISI H13 } & $\boldsymbol{C}$ & $\boldsymbol{S i}$ & $\boldsymbol{M n}$ & $\boldsymbol{P}$ & $\boldsymbol{S}$ & $\boldsymbol{C r}$ & $\boldsymbol{M o}$ & $\boldsymbol{N i}$ \\
& 0,418 & 1,08 & 0,348 & 0,017 & 0,001 & 5,12 & 1,36 & 0,044 \\
\hline $\boldsymbol{A} \boldsymbol{l}$ & $\boldsymbol{C o}$ & $\boldsymbol{C u}$ & $\boldsymbol{N b}$ & $\boldsymbol{T} \boldsymbol{i}$ & $\boldsymbol{V}$ & $\boldsymbol{W}$ & $\boldsymbol{S n}$ & $\boldsymbol{F e}$ \\
\hline 0,037 & $\leq 0,01$ & 0,018 & 0,006 & 0,009 & 1,09 & $<0,01$ & $<0,001$ & 90,455 \\
\hline \multirow{2}{*}{$\%$ AISI D2 } & $\boldsymbol{C}$ & $\boldsymbol{S i}$ & $\boldsymbol{M n}$ & $\boldsymbol{P}$ & $\boldsymbol{S}$ & $\boldsymbol{C r}$ & $\boldsymbol{M o}$ & $\boldsymbol{N i}$ \\
\cline { 2 - 9 } & 1,58 & 0,435 & 0,459 & 0,028 & 0,011 & 11,467 & 0,88 & 0,092 \\
\hline $\boldsymbol{A l}$ & $\boldsymbol{C o}$ & $\boldsymbol{C u}$ & $\boldsymbol{N b}$ & $\boldsymbol{T i}$ & $\boldsymbol{V}$ & $\boldsymbol{W}$ & $\boldsymbol{S n}$ & $\boldsymbol{F e}$ \\
\hline 0,001 & 0,011 & 0,037 & 0,008 & 0,003 & 0,84 & 0,058 & 0,03 & 84,092 \\
\hline
\end{tabular}


yerleştirilmesi için kullanılmış olması ve kesme sırasında oluşan sıcaklık değerlerinin daha net ölçülebilmesi için deneyler "kuru" şartlarda gerçekleştirilmiştir. Matkabın delme derinliği 3D olup, matkabın mekanik ve termal özellikleri Tablo 2'de verilmiştir.

Tablo 2. Deneylerde kullanılan matkabın mekanik ve termal özellikleri (Mechanical and thermal properties of drills used in the experiments).

\begin{tabular}{|c|c|c|}
\hline Mekanik Özellikler & $\begin{array}{c}\text { K25 grade } \\
\text { (Kaplaması) }\end{array}$ & $\begin{array}{c}\text { P25 grade } \\
\text { (Kaplamalı) }\end{array}$ \\
\hline Yoğunluk (gr/cm $\left.{ }^{3}\right)$ & 14,6 & 12,6 \\
\hline $\begin{array}{c}\text { Basma Dayanımı } \\
(\mathrm{MPa})\end{array}$ & 5000 & 4600 \\
\hline Young Modülü (GPa) & 590 & 550 \\
\hline Poisson Oranı & 0,22 & 0,22 \\
\hline $\begin{array}{c}\text { Termal İletkenlik } \\
(\mathrm{W} / \mathrm{mK})\end{array}$ & 70 & 45 \\
\hline $\begin{array}{c}\text { Termal genlesme } \\
\text { katsayı1s1 }\left(10^{6} / \mathrm{K}\right)\end{array}$ & 5,6 & 6,7 \\
\hline
\end{tabular}

Deneylerde kesme parametreleri, üretici firma kataloğunda (KARCAN) seçilen matkaplar için tavsiye edilen kesme parametreleri aralığında bir başlangıç değer seçilerek belirlenmiştir.

Ömür deneyleri standartlarında belirtilen her bir kesme şartı için en az dört farklı kesme hızı seçilmelidir şartından yola çıkarak, $60 \mathrm{~m} /$ dak olan başlangıç değeri, Standart Sayıların Geometrik Dizileri (R10, R20 ve R40) hakkındaki ISO standardına uygun olarak çoğaltılmıştır. $\mathrm{Bu}$ şartlar 1şığında seçilen dört farklı kesme hızı $(60,75,90,108$ $\mathrm{m} /$ dak) ve üç farklı ilerleme değeri $(0.15,0.20$ ve 0.25 $\mathrm{mm} / \mathrm{dev})$ kullanılarak deneyler gerçekleştirilmiştir. Her bir deney numunesinin diş çapı $25 \mathrm{~mm}$ ve delik boyu $35 \mathrm{~mm}$ olacak şekilde olacak şekilde hazırlanmıştır. Deneyler Gazi Üniversitesi Teknik Eğitim Fakültesi, Makine Eğitimi Bölümü Talaşlı Üretim Anabilim Dalı'nda bulunan Johnford VMC550 marka $\mathrm{CNC}$ dik işleme merkezinde gerçekleştirilmiştir.

Deneylerde, inconel kılıflı NiCr-Ni ve $1 \mathrm{~mm}$ çapında olan 1sıl çiftler, literatürdeki bazı uygulamalar baz alınarak $(11,14)$ matkabın soğutma kanallarına yerleştirilmiş ve böylece isıl çiftlerin doğrudan kesme bölgesine ulaşması hedeflenmiştir. Kanal çıkışları matkabın kesme kenarının hemen arkasında, kesme genişliğinin tam ortasında yer aldığından, takım talaş ara yüz sıcaklığının en üst düzeyde ölçülebilmesi amaçlanmıştır (Şekil 2). Elde edilen veriler, Pico marka 8 kanallı data logger yardımı ile Pico Log Recorder yazılımı eşliğinde grafiklere dönüştürülmüştür. Deneysel çalışmaya ait test düzeneği fotoğrafi ve matkap-iş parçası konum fotoğrafi Şekil 3'te verilmiştir.

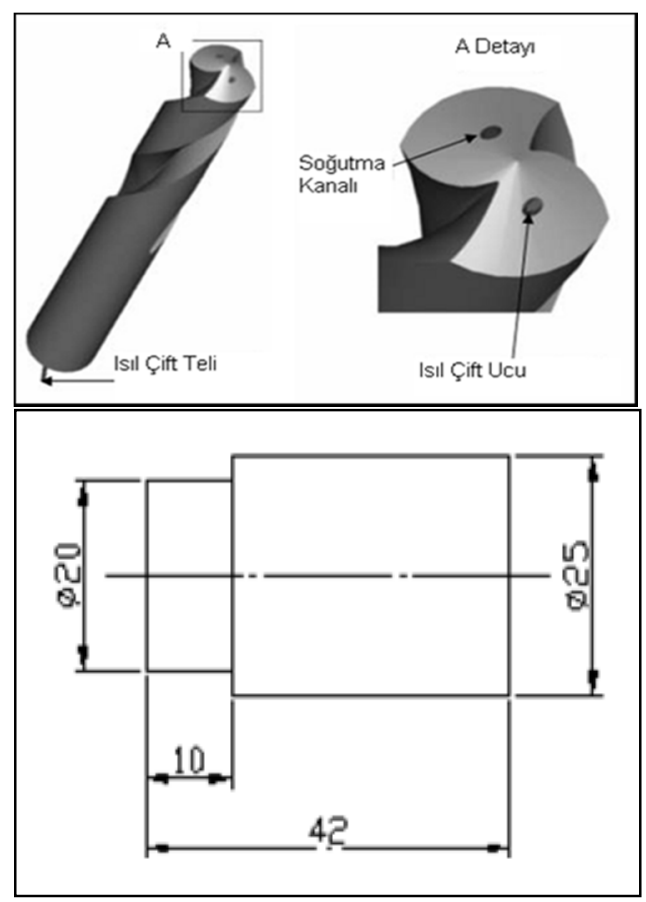

Şekil 2. Deneylerde kullanılan numune ölçüleri ve takımda konumlandırılmış ısıl çiftler (Dimensions of the samples and thermocouples placed in drill used in the experiments).

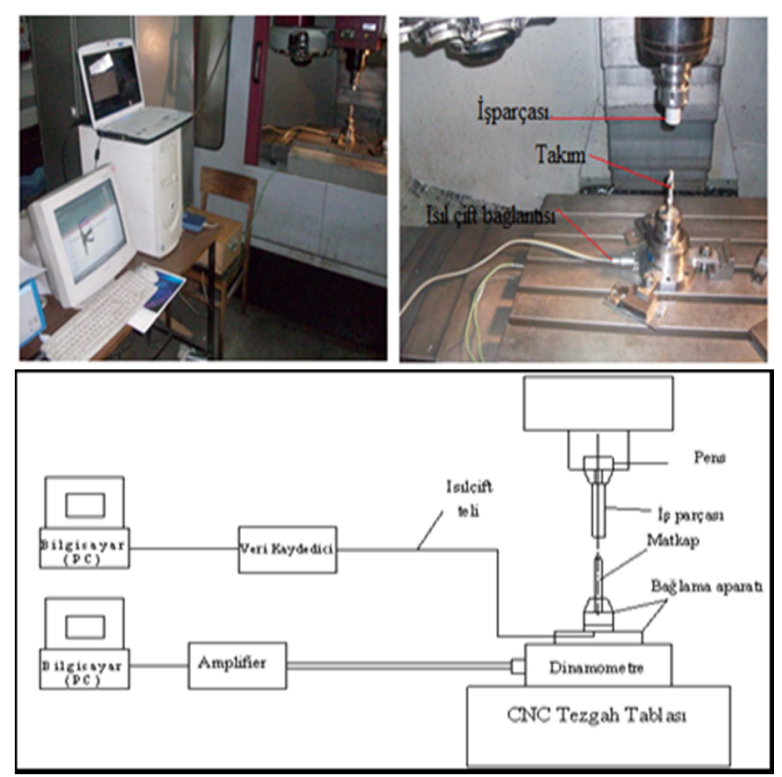

Şekil 3. Deneysel çalışmaya ait test düzeneğinin şematik gösterimi ve fotoğrafi (The photo of the test apparatus and schematic representation belonging to the experimental work)

\section{DENEYSEL SONUÇLAR VE TARTIŞMA (RESULTS AND DISCUSSION)}

AISI H13 ve AISI D2 malzemelerinin kaplamasız ve kaplamalı karbür matkaplarla delinmesi esnasında kesme hızı ve ilerleme miktarı parametrelerine bağlı olarak, kesme bölgesinde oluşan sıcaklık değişimleri Şekil 4'deki grafiklerde, AISI H13 ve AISI D2 malzemelerinin delinmesi sonrası kullanılan matkabın ve işlem esnasında oluşan talaş şeklinin fotoğrafları Şekil 5 - Şekil 8'de gösterilmiştir. 
Şekil 4'deki grafikler incelendiğinde, bütün deney sonuçlarında AISI H13 ve AISI D2 malzemelerinin kaplamasız ve kaplamalı matkaplarla delinmesi esnasında oluşan sıcaklık değerleri, ilerleme miktarının artışına karşın azalma göstermiştir. $\mathrm{Bu}$ durumu; ilerleme miktarı artışının matkap kesici kenarlarının daha az sürtünmeye yol açmasına atfedebiliriz. Çünkü düşük ilerleme miktarında matkap kesici kenarının kaldırdığı toplam talaş uzunluğu ile ilerleme miktarının artması sonucu kaldırılan toplam talaş uzunluğu farklıdır. İlerleme miktarının artması neticesinde matkap kesici kenarı, düşük ilerleme miktarında kaldırılan toplam talaş uzunluğundan daha kısa uzunlukta talaş kaldırır. Matkap kesici kenarı ile talaş arasındaki sürtünmeden dolayı sıcaklığın ortaya çıktığını düşünürsek, ilerleme miktarının artı̧̧ı sonucu talaş- matkap kesici kenar temasının kısa olması ortaya çıkan sıcaklığın daha az olmasını sağlamıştır. Sonuç olarak ilerleme miktarının artmasına karşın sıcaklık değerlerinde düşüş olması normal bir sonuçtur. Ayrica kesme bölgesinde oluşan sıcaklığın yaklaşık olarak \% 80'nin talaşla atıldığını $[2,19]$ kabul edecek olursak, ilerleme miktarının artmasıyla birlikte matkabın delik içerisinde hızlı ilerlemesi ve buna bağlı olarak da helis kanallarından talaşın daha hızlı tahliyesi sıcaklığın azalmasına ilave bir katkı sağlamıştır.

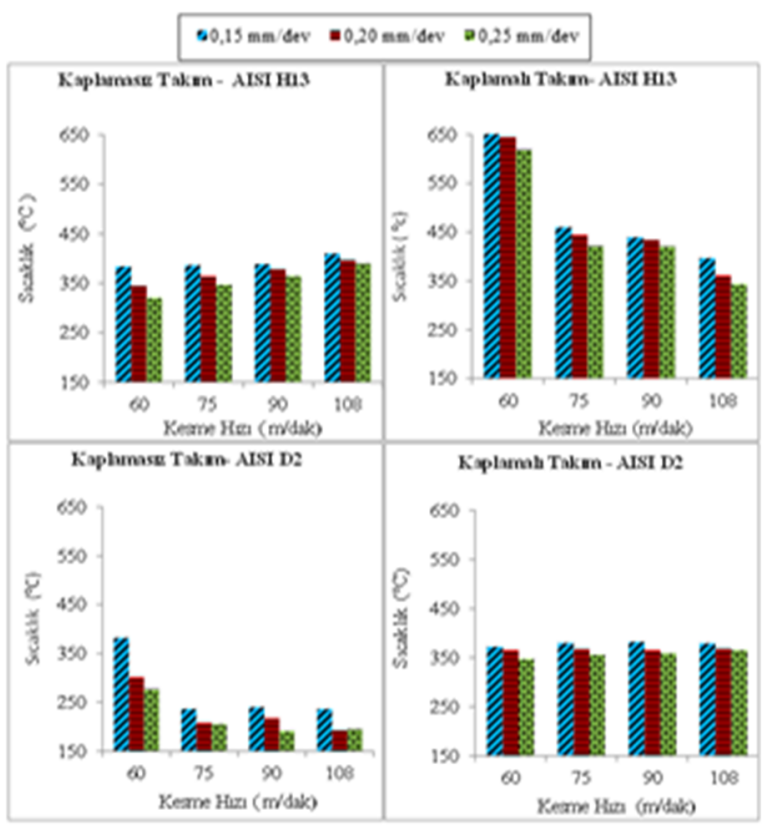

Şekil 4. Kesme bölgesinde meydana gelen sıcaklıkların karşılaştırılması (Comparison of the cutting zone temperatures)

AISI H13 malzemesinin kaplamasız matkaplarla işlenmesi esnasında oluşan sıcaklık, kesme hızının artı̧̧ıla birlikte artış göstermiştir. Şekil 5'deki AISI H13-Kaplamasız matkap ve oluş̧urduğu talaş şekli incelendiğinde, AISI H13 malzemesinin $600^{\circ} \mathrm{C}$ 'ye kadar sertliğini kaybetmemesi [25] ve kesme hızının artışılla birlikte matkap ucunda başlayan aşınmanın kesici kenarlara kadar uzanması sıcaklığın artmasını sağlamıştır. Çünkü matkap uç kısmı daha çok ezerek talaş kaldırmaya çalışır ve bu matkabın uç bölgesi yüksek gerilmelere maruz kalır.

Yüksek gerilmeler neticesinde aşınan matkabın uç kısmı delik delme işlemi için daha fazla enerji harcar. Talaş kaldırma işleminde harcanan enerjinin hemem hemen çoğunun 1sıya dönüştüğü düşünüldüğünde, kesme hizının armasıyla birlikte hem matkap ucunda oluşan aşınma hem de kesici kenarlarda oluşan aşınmaların talaş kaldırmak için daha fazla enerji tüketmesi sıcaklığın artmasını sağlamıştır. Ayrıca oluşan talaşın yapışmalı sürekli talaş [26] oluşu sıcak artışına katkı sağlamıştır. Örneğin ilerleme miktarının \% 33'lük artışına karşılık sıcaklık değerleri yaklaşık \% 10'luk, ilerleme miktarının \% 66 artı̧ına karşılık sıcaklık değerlerinde yaklaşı \% 17'lik bir azalma söz konusudur. Fakat kesme hizının \% 25 artmasiyla sıcaklık yaklaşık \% 0,5 , kesme hızının \% 50 'lik artmasıyla sıcaklık yaklaşık \% 1,5 , kesme hızının \% 63 'lük artmasıyla sıcaklık \% 9 artış göstermiştir.

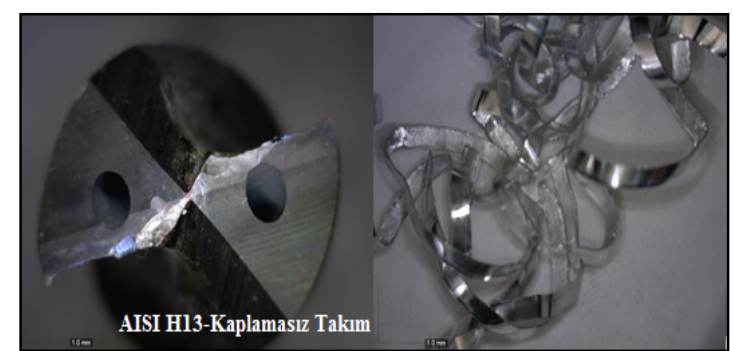

Şekil 5. AISI H13- Kaplamasız takım ve oluşan talaş (Uncoating tool and chip)

AISI H13 malzemesinin kaplamal1 matkaplarla delinmesinde ise kesme hızının artmasına karşın sıcaklık değerlerinde azalma gözlemlenmiş̧ir. $\mathrm{Bu}$ durum artan kesme hizıyla birlikte kayma düzlem açısının artması sonucu ikinci deformasyon bölgesinde yapışan malzemenin akma dayanımının ve ikinci deformasyon bölgesinde yapışma bölgesinin azalmasıyla açıklanabilir [27].

Şekil 6'daki AISI H13-Kaplamalı matkap ve oluşan talaş şekli incelendiğinde, matkapta aşınma oluşmadığı ve oluşan talaş şeklinin kabul edilebilir şekilde [26] olduğu görülmektedir. Kaplamalı matkapların kaplama özelliğinden dolayı aşınma dirençlerinin yüksek ve sürtünme katsayılarının düşük olduğundan hem matkap performansinda düşme olmamış hem de talaş matkaba yapışmadan uzaklaştırılmıştır. Talaşlı imalatta oluşan 1sının yaklaşık \% 80'nin talaşla atıldığını $[2,14,18,19]$ düşünürsek, kesme hızının artmasıyla birlikte talaş tahliyesinde hızlanma ve daha az sürtünme sıcaklığın azalmasını sağlamıştır. Örneğin ilerleme miktarının \% 33'lük artışına karşılık sıcaklık değerleri yaklaşık \% 9'luk, ilerleme miktarının \% 66 artışına karşılık sıcaklık değerlerinde yaklaşı \% $15^{\prime}$ 'lik bir azalma söz konusudur. Fakat kesme hizının \% 25 artmasiyla sıcaklık yaklaşık \% 32, kesme hızının \% 50’lik 
artmasıyla sıcaklık yaklaşık \% 35, kesme hızının \% 80'lik artmasıyla sıcaklık \% 44 azalış göstermiştir. AISI D2 çeliğinin kaplamasız matkaplarla delinmesi esnasında oluşan sıcaklık kesme hızının artmasıyla birlikte azalma göstermiştir.

$\mathrm{Bu}$ durumu kesme hızının artmasıyla birlikte talaş tahliyesinin hızlanmasina atfedebiliriz.

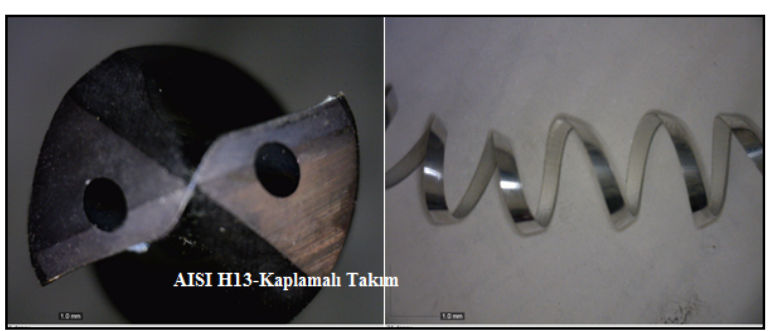

Şekil 6. AISI H13- Kaplamalı takım ve oluşan talaş şekli (Coating tool and chip form).

Şekil 7'deki fotoğraf incelendiğinde, matkapta aşınmanın olduğu görülmektedir. Fakat kesme bölgesinde oluşan sıcaklığın matkap-talaş-iş parçası arasında dağılımı [19] ve malzemenin özelliğinden [25] dolayı oluşan talaşın kabul edilebilir şekilde olduğu görülmektedir [26]. AISI D2 malzemesi kaplamsız matkaplarla delinmesi esnasında oluşan talaş şeklinin sürekli talaş [26] olması, kesme hızının artmasıyla talaş tahliyesi hızlanmış ve kesme hızı artışı sıcaklığın azalmasını sağlamıştır. Örneğin ilerleme miktarının \% 33'lük artışına karşılık sıcaklık değerleri yaklaşık \% 20'lik, ilerleme miktarının \% 66 artışına karşılık sıcaklık değerlerinde yaklaşı1k \% 28'ilk bir azalma olmuştur. Keme hızında ise \% 25'lik artış sıcaklığı yaklaşık \% 10, kesme hızında \% 50’lik artış sıcaklığı yaklaşık \% 10, kesme hızında \% 80'li artış sıcaklığı \% 10 azaltııştır.

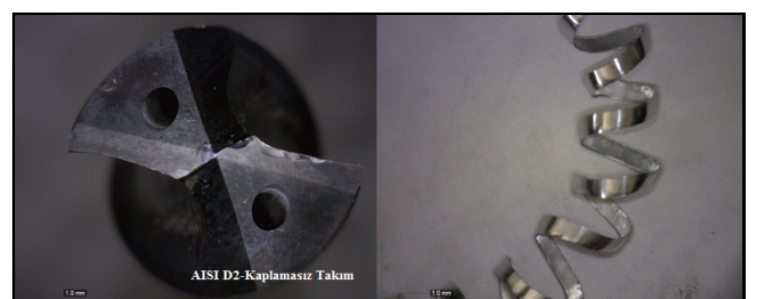

Şekil 7. AISI D2- Kaplamasız takım ve oluşan talaş (Uncoating tool and chip)

Fakat AISI D2 malzemesinin kaplamalı takımlarla delinmesi esnasında aynı durum gözlenmemiştir. Kesme hızının artması, sıcaklığın azalmasında etkili olmamıştır. Tam aksine önemsenmeyecek derecede artış tespit edilmiştir. $\mathrm{Bu}$ durum kesme bölgesinde oluşan sıcaklığın kaplamalı matkabın 1sıl iletkenlik katsayısının düşüklüğünden dolayı sıcaklığın talaş ve iş parçası arasında paylaşılması sonucu oluşan talaşın, sıcaklık artışıyla beraber yapışmalı sürekli talaş şekline dönüşmesidir. Şekil 8'deki AISI D2Kaplamalı matkap ve oluşan talaş şekli incelendiğinde matkap ucunda talaş yapışmaları görülmektedir. Bu yapışma kesme hızının artması sonucu artan sürtünmenin sıcaklığı artırması ve buna bağlı olarak ta AISI D2 malzemesinin $200{ }^{\circ} \mathrm{C}$ 'nin üzerinde sertliğini kaybetmesi [25] oluşan talaşın yapışmalı sürekli talaş olmasını sağlamıştır. Yapışmalı sürekli talaş oluşumunun tahliyesinde yaşanan güçlükler sıcaklık değerlerinin az da olsa yükselmesine yol açmıştır. Örneğin $0,25 \mathrm{~mm} / \mathrm{dev}$ ilerleme miktarı ve $60 \mathrm{~m} / \mathrm{dak}$ kesme parametrelerinde sicaklık $347{ }^{\circ} \mathrm{C}$ iken, aynı ilerleme miktarı ve $108 \mathrm{~m} /$ dak kesme hızı için sıcaklık $365{ }^{\circ} \mathrm{C}$ olarak ölçülmüştür. Kesme hızının \% 80 artmasına karşılık sıcaklık yaklaşık \% 5 oranında artmıştır.

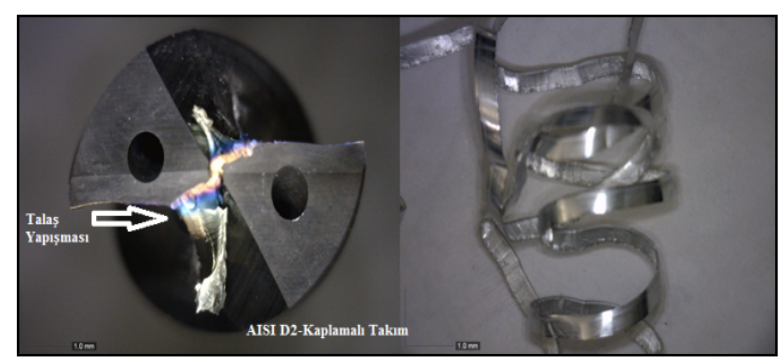

Şekil 8. AISI D2- Kaplamalı takım ve oluşan talaş (Coating tool and chip).

AISI H13 ve AISI D2 malzemelerinin kaplamalı matkaplarla delinmesi esnasında oluşan sicaklık, kaplamasız matkaplarla yapılan işlemler esnasında oluşan sıcaklıktan daha fazla çıkmıştır (Şekil 5). Bu durum kesme bölgesinde oluşan sıcaklığın matkap-iş parçası-talaş arasında dağılımıyla açıklanabilir. Kesme bölgesinde oluşan bu sıcaklığın \% 70-80'ni talaşla tahliye olurken, \% 5-10'nu iş parçasına ve geri kalan \% 10-20'si ise matkaba transfer olduğunu düşünülmektedir [2,19]. Buna bağlı olarak kaplamalı matkabın 1sı iletim katsayısının (Tablo 2) kaplamasız matkaplara göre \% 40 daha az olması, kaplamalı matkabın transfer etmesi gereken ısının kapalı ortam olan delik içerisine yayılarak sıcaklık artışına neden olduğu düşünülmektedir.

Şekil 5'deki grafikler iş parçaları malzemeleri açısından incelendiğinde, AISI H13 malzemesinin kaplamasız ve kaplamalı matkaplarla yapılan delik delme işlemi esnasında oluşan sıcaklık AISI D2 malzemesinin işlenmesi esnasında oluşan sıcaklıktan daha yüksek çıkmıştır. $\mathrm{Bu}$ durum; malzemelerin yapısal özelliğinden kaynaklanmaktadır. Farklı mikro yapıya ve farklı kimyasal bileşim oranlarına sahip bu malzemelerin içerisinde bulunan alaşım elementleri oranları ve bu elementlerin oluşturduğu özelliklerde farklıdır [25]. AISI H13 malzemesinin AISI D2 malzemesine göre mikro yapısının küçük boyutlu tanelerden oluşması ve homojen dağılımlı yapıda olması malzemenin deformasyon kabiliyetini azaltmaktadır. Ayrıca malzemenin yapısına bulunan kalıntılar (oksit, sülfür veya nitrür) işlenebilirliği belirleyen unsurlardır. Örneğin, talaş oluşumu esnasında plastik deformasyona uğrayan $\mathrm{MnS}$ 
(mangan sülfat) kalıntıları düşük mukavemetli düzlemler oluşturdukları için daha az enerji harcanarak deforme edilirler. $\mathrm{Bu}$ durum birincil kayma bölgesinde deformasyonu kolaylaştırdığ1 için daha az sürtünme gerçekleşecek ve buna bağlı olarak ta daha az sıcaklık oluşacaktır [27,28]. Tüm bu bilgiler 1şı̆̆ında, Tablo 1'de AISI H13 çeliğinin kimyasal kompozisyonunda bulunan kükürt ve mangan oranı, AISI D2 çeliğinin kimyasal kompozisyon oranından daha azdır. Bu nedenle AISI H13 malzemesinin delinmesi esnasında oluşan talaş, AISI D2 malzemesinden elde edilen talaşa göre daha sünek olmuştur. Yapışmalı sürekli talaş matkap ucuna ve helis kanallarına yapışarak sıcaklığı artırmıştır. Bunun yanında talaş tahliyesin de yaşanan güçlükler ve talaş kaldırmak için daha fazla enerji ve bu enerjinin 1sıya dönüşmesi, AISI H13'ün delinmesinde oluşan sicaklığın AISI D2'nin delinmesi esnasında oluşan sıcaklıktan daha fazla olmasına yol açmıştır.

\section{SONUÇLAR (CONCLUSIONS)}

AISI H13 ve AISI D2 malzemelerinin kaplamasız ve kaplamalı matkaplarla delinmesi esnasında oluşan sıcaklık kesme parametrelerine, takım kaplama tipi ve malzeme cinsine göre karşılaştırılmıştır. $\mathrm{Bu}$ çalışma ile aşağıdaki sonuçlara ulaşılmıştır;

- Delik delme işleminde sıcaklığın azalmasında ilerleme miktarı önemli bir faktördür. İlerleme miktarının artması sıcaklığın azalmasını sağlamaktadır.

- Matkapta ciddi aşınma olmaması durumunda kesme hızı artışı sıcaklığın azalmasına yol açmaktadır. Aksi halde kesme hızının artmasıyla birlikte matkapta oluşan aşınmalar sıcaklığın artmasına neden olmaktadır.

- Kaplamalı matkaplarla yapılan delik delme işlemleri esnasında oluşan sıcaklıklar kaplamasız matkaplarla yapılan işlemlerde elde edilen sıcaklıklardan daha fazla çıkmıştır. Bunun nedeni olarak da kaplamalı matkabın düşük 1Sı iletim katsayısı nedeniyle kesme bölgesinde oluşan sıcaklığın matkaba transfer olamaması ve delik içerisine yayılmasıdır.

- AISI H13 malzemesinin kaplamasız ve kaplamalı matkaplarla işlenmesi esnasında oluşan sıcaklıklar AISI D2 malzemesinin işlenmesi esnasinda oluşan sicaklıklardan daha fazla çıkmıştır. $\mathrm{Bu}$ durumun nedeni malzemelerin yapısal ve kimyasal farklılıklarından kaynaklanmıştır.

\section{TEŞEKKÜR (ACKNOWLEDGEMENT)}

Bu çalışmayı, KBÜ-BAP-13/1-DR-002 kodlu proje ile destekleyen Karabük Üniversitesi, Bilimsel Araştırma Proje Koordinatörlüğü’ ne teşekkür ederiz.

\section{KAYNAKLAR (REFERENCES)}

1. Sandvik Coromant Technical Editorial Department, Modern Metal Cutting-A Practical Handbook, Tofters Tryckeri AB, İsveç, XI-8, 133, 1994

2. Şahin, H.M., Acır. A.,"Talaş Kaldırma İşlemlerinde Kesici Takım ve Talaş Arasında Oluşan Sicaklık Dağılımının Sonlu Farklar Metodu ile Analizi', Politeknik Dergisi Journal of Polytechnic, Cilt 6, No 3, 541-549, 2003

3. Ueda,T., Nozaki, R., Hosokawa, A., "Temperature Measurement of Cutting Edge in Drilling - Effect of OilMist"-,CIRP Annals Manufacturing Technology, Cilt 56, No 1, 93, 2007.

4. Ghani, J.A, Choudhury, I.A, Masjuki, H.H., "Performance of P10 TiN Coated Carbide Tools When End Milling AISI H13 Tool Steel at High Cutting Speed", Journal of Materials Processing Technology, 153-154, 2004.

5. Umbrello, D.,Rizzuti, S., Outeiro, J.C., Shivpuri, R., M'Saoubi,. R., "Hardness-Based Flow Stress for Numerical Simulation of Hard Machining AISI H13 Tool Steel', Journal of Materials Processing Technology, Cilt 199, 64-73, 2008.

6. Moon, Y. H, Kim, J. W., Lee, D. W., "Machining Characteristics of Electroslag Cast Steel for HotWorking Tools", Journal of Materials Processing Technology, 153-154 - 654-659, 2004.

7. Davim, J. P., Figueira, L., "Machinability Evaluation in Hard Turning of Cold Work Tools Teel (D2) With Ceramic Tools Using Statistical Techniques", Materials and Design, Cilt 28, 1186-1191, 2007.

8. Poulachon, G., Bandyopadhyay, B.P., Jawahir, I.S., Pheulpin, S., Seguin, E., "Wear Behavior of CBN Tools While Turning Various Hardened Steels", Wear, Cilt 256, 302-310, 2004.

9. Silva, M. B., Wallbank, J.,"Cutting Temperature: Prediction and Measurement Metods-a Review" Journal of MaterialsProcessingTechnology, Cilt 88, 195-202, 1999.

10. Haan, D. M., Batzer, S. A., Olson, W. W., Sutherland, J. W., "An Experimental Study of Cutting Fluid Effects in Drilling" Journal of Materials Processing Technology, Cilt 71, 305313, 1997.

11. Bağci, E., Özcelik, B., "Finite element and experimental investigation of temperature changes on a twistdrill in sequential dry drilling" Int J. Adv. Manufacturing Technology, Cilt 28, 680-687, 2006.

12. Brandao, L. C., Coelho, R T., Lauro, C. H., "Contribution to Dynamic Characteristics of the Cutting Temperature in the Drilling Process Considering One Dimension Heat Flow', Applied Thermal Engineering, Cilt 31, 38063813, 2011. 
13. Coz, G. L., Marinescu, A. D., Dudzinski, D., Velnom, L., "Measuring Temperature of Rotating Cutting Tools: Application to MQL Drilling and Dry Milling of Aerospace Alloys", .Applied Therma Engineering, Cilt 36, 434-441, 2012.

14. Yağmur, S,. Acır, A., Şeker, U., Günay, M., "Delik Delme İşlemlerinde Kesme Parametrelerinin Kesme Bölgesindeki Sıcaklığa Etkisinin Deneysel İncelenmesi” Journal of The Faculty of Engineering and Architecture of Gazi University, Cilt 28, No 1, 1-6, 2013.

15. Kaynak, Y., Matkap ile Delik Delme Esnasında Kesme Parametrelerinin Kesme Kuvveti ve Sıcaklığın Değişimine Etkisinin Deneysel Olarak İncelenmesi, Yüksek Lisans Tezi, Marmara Üniversitesi Fen Bilimleri Enstitüsü, 58-69, 2006.

16. Sousa, P. F.B.,Borges, V. L., Pereira, I. C., Silva, M.B., Guimarães, G., "Estimation of Heatflux and Temperature Field During Drilling Processusing Dynamic Observers Based on Green'sfunction", Applied Thermal Engineering, Cilt 48, 144-154, 2012.

17. Li, R., Shin. A. J., "Spiral Point Temperature and Stress in High-Throughput Drilling of Titanium", International Journal of Machine Tools \& Manufacture, Cilt 47, 2005-2017, 2007.

18. Kayır, Y., Usta, M., "Torna Tezgahlarında Matkapla Delik Delme İşlemlerinde Kesme Kuvvetleri ve Sicaklığın Ölçülmesi”, International Iron \& Steel Symposium, Karabük, 1284-1295, 2012.

19. Aydın, M., Uçar, M., Cengiz, A., “AISI 304 Östenitik Paslanmaz Çeliğin Kuru Tornalanabilmesine Kesme Parametrelerinin Etkisi”, II. Ulusal Tasarım İmalat ve Analiz Kongresi, Balıkesir, 85-94, 2010.
20. Basso , R. L. O., Pastore , H. O., Schmidt, V., Baumvol, I. J.R., Abarca S. A.C., "Microstructure and Corrosion Behaviour of Pulsed PlasmaNitrided AISI H13 Tool Steel", Corrosion Sience, Cilt 52, 3133-3139, 2010.

21. Genel ,K., " Boriding Kinetics of H13 Steel”, Vacuum,Cilt 80, 451-457, 2006.

22. Oliveira, C.K.N., Riofanob, R.M. M., Castelettib, L.C., "Formation of Carbide Layers on AISI H13 and D2 Steels by Treatment in Molten Borax Containing Dissolved Both $\mathrm{Fe}-\mathrm{Nb}$ and $\mathrm{Fe}-\mathrm{Ti}$ Powders", Materials Letters, Cilt 59, 17191722, 2005.

23. Kheirandish, S., Noorian, A., " Effect of Niobium on Microstructure of Cast AISI H13 Hot Work Tool Steel', Journal of Ironand Steel Research, International, Cilt 15, No 4, 61-66, 2008.

24. Koneshlou, M., Meshinchi, A. K., Khomamizadeh, F., "Effect of cryogenic treatment on microstructure, mechanical and wear behaviors of AISI H13 hot work tool steel', Cryogenics, Cilt 51, 55-61, 2011.

25. Internet: Türkiye Osamanlı Alaşımlı Çelikler San. ve Tic. Ltd., "Takım Çeliklerinde Elementlerin Etkisi”, http//www.osmanlibohler.com/upload/pdf/tenikbilgiler/TakımTakım_Celikleri.pdf, 2013.

26. Internet: Türkiye, "Talaşlı Imalat, Talaş Kaldırma ve Talaş Çeşitleri", http://muhserv.atauni.edu.tr/makine/akgun/Docs/ alisilmamis $/ 04$ Tala $\% \mathrm{C} 5 \% 9 \mathrm{Fl} \% \mathrm{C} 4 \% \mathrm{~B} 1 \% 20 \% \mathrm{C}$ 4\%B0malat.pdf, 2013.

27. Trent EM., Metal Cutting, Butterworths Pres, London, 1989.

28. Çakır, M.C., Modern Talaşıı İmalatın Esasları, Vipaş A.Ş., Bursa, 1999. 